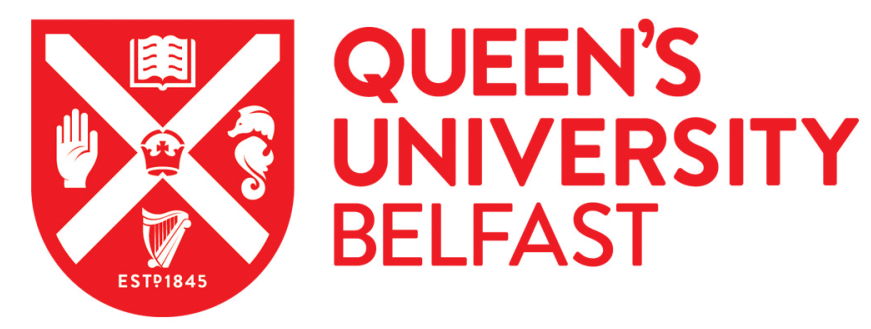

\title{
Lignin-based hydrogels with "super-swelling" capacities for dye removal
}

Dominguez Robles, J., Peresin, M. S., Tamminen, T., Rodríguez, A., Larrañeta, E., \& Jääskeläinen, A-S. (2018). Lignin-based hydrogels with "super-swelling" capacities for dye removal. International Journal of Biological Macromolecules, 115, 1249-1259. https://doi.org/10.1016/j.ijbiomac.2018.04.044

\section{Published in:}

International Journal of Biological Macromolecules

\section{Document Version:}

Peer reviewed version

\section{Queen's University Belfast - Research Portal:}

Link to publication record in Queen's University Belfast Research Portal

\section{Publisher rights}

Copyright 2018 Elsevier.

This manuscript is distributed under a Creative Commons Attribution-NonCommercial-NoDerivs License

(https://creativecommons.org/licenses/by-nc-nd/4.0/), which permits distribution and reproduction for non-commercial purposes, provided the author and source are cited.

\section{General rights}

Copyright for the publications made accessible via the Queen's University Belfast Research Portal is retained by the author(s) and / or other copyright owners and it is a condition of accessing these publications that users recognise and abide by the legal requirements associated with these rights.

\section{Take down policy}

The Research Portal is Queen's institutional repository that provides access to Queen's research output. Every effort has been made to ensure that content in the Research Portal does not infringe any person's rights, or applicable UK laws. If you discover content in the Research Portal that you believe breaches copyright or violates any law, please contact openaccess@qub.ac.uk. 


\section{Accepted Manuscript}

Lignin-based hydrogels with "super-swelling" capacities for dye removal

Juan Domínguez-Robles, María Soledad Peresin, Tarja Tamminen, Alejandro Rodríguez, Eneko Larrañeta, Anna-Stiina Jäskeläinen

PII: $\quad$ S0141-8130(18)30175-2

DOI: $\quad$ doi:10.1016/j.ijbiomac.2018.04.044

Reference: BIOMAC 9452

To appear in:

Received date: $\quad$ 11 January 2018

Revised date: $\quad 5$ April 2018

Accepted date: $\quad 9$ April 2018

Please cite this article as: Juan Domínguez-Robles, María Soledad Peresin, Tarja Tamminen, Alejandro Rodríguez, Eneko Larrañeta, Anna-Stiina Jääskeläinen , Ligninbased hydrogels with "super-swelling" capacities for dye removal. The address for the corresponding author was captured as affiliation for all authors. Please check if appropriate. Biomac(2017), doi:10.1016/j.ijbiomac.2018.04.044

This is a PDF file of an unedited manuscript that has been accepted for publication. As a service to our customers we are providing this early version of the manuscript. The manuscript will undergo copyediting, typesetting, and review of the resulting proof before it is published in its final form. Please note that during the production process errors may be discovered which could affect the content, and all legal disclaimers that apply to the journal pertain. 


\title{
Lignin-based hydrogels with "super-swelling" capacities for dye removal
}

Juan Domínguez-Robles ${ }^{1 *}$, María Soledad Peresin ${ }^{2,3}$, Tarja Tamminen ${ }^{2}$, Alejandro Rodríguez ${ }^{1}$, Eneko Larrañeta ${ }^{4}$, Anna-Stiina Jääskeläinen ${ }^{2^{*}}$

${ }^{1}$ Chemical Engineering Department, Faculty of Science, Universidad de Córdoba, Building Marie-Curie, Campus of Rabanales, 14014 Córdoba, Spain.

${ }^{2}$ VTT Technical Research Centre of Finland Ltd, P.O. Box 1000, 02044 Espoo, Finland.

${ }^{3}$ Present address: Forest Products Development Center, School of Forestry and Wildlife Sciences, Auburn University, 602 Duncan Dr., Auburn, AL, 36849-5418, USA.

${ }^{4}$ School of Pharmacy, Queen's University Belfast, 97 Lisburn Road, Belfast BT9 7BL, United Kingdom.

*Corresponding author: z42doroj@uco.es (Juan Domínguez-Robles); AnnaStiina.Jaaskelainen@vtt.fi (Anna-Stiina Jääskeläinen).

Postal address: University of Córdoba, Campus of Rabanales, Marie-Curie Building, Ctra. N-IV, km. 396, 14014 Córdoba, Spain (J. Domínguez-Robles); VTT Technical Research Centre in Finland, P.O. Box 1000, 02150 Espoo, Finland (A.-S. Jääskeläinen).

\begin{abstract}
Lignin is a complex natural polymer and it is one of the main constituent of the lignocellulosic biomass. Moreover, it is a bio-renewable material and it is available in large amounts as by-product of residues from the wood and paper industries. Ligninbased hydrogels with high swelling capabilities were prepared by crosslinking poly
\end{abstract}


(methyl vinyl ether co-maleic acid) and different technical lignins in ammonium and sodium hydroxide solutions. The produced hydrogels showed a wide range of water absorption capacities varying from 13 to $130 \mathrm{~g}$ of water per $1 \mathrm{~g}$ of sample. It was observed that materials with higher water uptake poorer mechanical performance, as evaluated in terms of storage and loss modulus ( $G^{\prime}$ and G', respectively). Methylene blue (MB) was used as a model dye to evaluate the adsorption and release capabilities of the lignin hydrogels. Results suggested that these hydrogels showed a high MB load efficiency, which ranged from $440 \mathrm{mg}$ to $840 \mathrm{mg} / \mathrm{g}$. On the contrary, the percentages of MB released depended on the negative surface charge of the hydrogels, showing values which ranged from 0.06 to $0.35 \%$. Thus, these materials have potential to be used as adsorbents for the removal of organic dyes from waste water.

Keywords: Lignin hydrogels; Water absorption; Dye removal.

\section{Introduction}

Isolation and utilization of lignin as one of the major constituents of lignocellulosic biomass is increasingly moving into the limelight of biorefinery strategies [1]. Lignin is a complex aromatic heteropolymer synthesised mainly from three monomers differing in their number of methoxyl groups: p-coumaryl, coniferyl, and sinapyl alcohols [2]. Lignin is the second most abundant biopolymer after cellulose on the planet and it constitutes between 15 and $40 \%$ of the dry matter of plant biomass [3,4].

Currently, worldwide chemical wood pulping industry produces $c a .70 \mathrm{Mt}$ of lignin [5]. However, the largest part of this polymer is burned to generate energy, while a small amount of it, estimated at $1-2 \%$, is isolated from black liquors and used for a wide variety of materials applications [5]. Therefore, lignin and especially technical lignins 
are attractive raw materials for several industrial purposes with significant sustainability and green chemical connotations [4,5].

The use of lignin and other bio-renewable polymers have attracted a greater attention of the research community due to the advantages such as their low cost and/or biodegradability [6]. Bio-renewable polymers coming from lignocellulosic biomass have a significant potential to reduce the dependence on petrochemical-based feedstock [7]. Recently, multiple research works have been published describing novel uses of lignin such as binder material in lithium batteries [8] or raw material for the production of new polymeric materials $[9,10]$. In addition to this, in the last few years, several studies have focused on the use of lignin as starting material for the production of hydrogels and aerogels, using for toxic compound removal [11,12] and as coating materials to prepare slow-release fertilizers [13], among other uses.

Hydrogels are materials made of crosslinked polymeric network structures that can absorb and retain significant amounts of water or biological fluids without being dissolved [14,15]. These physico-chemical properties of hydrogels make them suitable materials to be used for drug delivery applications [15-17], tissue engineering [16,18], wound dressings [19] or agricultural/environmental applications [13,20]. The latter includes the use of lignins for removal of contaminants from water [11,21,22]. This is a promising approach as lignin contains a high concentration of functional groups that can form electrostatic interactions with a wide variety of compounds present in residual waters.

Different toxic organic compounds can be found in processing residual water streams. Organic dyes are included in this group of molecules as they are commonly used in several industries such as textile, cosmetic or papermaking [23]. It is estimated that 
about $2 \%$ of these compounds are directly discharged into water resources $[24,25]$. These organic dyes, can be very harmful for the aquatic life and food chain due to mutagenic and carcinogenic effects even at low concentrations [26,27]. Several methods, such as coagulation-flocculation, oxidation, membrane separation or electrochemical processes, could be employed to remove these toxic compounds $[28,29]$. To this end, adsorption is an effective and simple method to remove pollutants from wastewater [26]. In this scenario, hydrogels represent valuable alternative as water purification medium.

The present work describes the synthesis and characterization of lignin-based hydrogels for water purification applications. The hydrogels were synthetized by crosslinking lignin with poly (methyl vinyl ether co-maleic acid) (PMVE/MA) using a simple thermal process. Overall, these new hydrogels can be considered a green material as the process do not use any toxic solvent/reagent and it is based on a renewable biopolymer. Different types of lignins obtained from different raw materials and processed with different pulping treatments were used in this study. The resulting hydrogels were characterised by Fourier transform infrared spectroscopy (FTIR), water uptake capacity, mechanical properties and scanning electron microscopy (SEM) analysis. Finally, the dye adsorption and desorption capacities of the hydrogels were studied.

\section{Materials and methods}

\subsection{Materials}

Gantrez $^{\circledR}$ S-97, copolymer of methyl vinyl ether and maleic acid, with a molar mass of $1,200,000$ was a donated from Ashland, Barcelona, Spain. Ammonia 30\% $\left(\right.$ as $\left.\mathrm{NH}_{3}\right)$ and $\mathrm{NaOH} 99 \%$ (as pellets) were purchased form PanReac Appli Chem, Helsinki, Finland. Methylene blue (MB) was supplied by Sigma-Aldrich, Dorset, UK. 
Lignin samples used in this study were obtained through three different pulping processes and all of them were recovered by precipitation from organosolv, soda and kraft liquors produced in these processes. Organosolv pulping process was performed under the following operating conditions: $210^{\circ} \mathrm{C}$ for $60 \mathrm{~min}$, using aqueous $60 \%$ ethanol as the reagent, being the solid/liquid ratio 1:10 [30]. Soda pulping process was performed at $100^{\circ} \mathrm{C}$, for $150 \mathrm{~min}$, containing $7 \% \mathrm{NaOH}$ (o.d.) and the solid/liquid ratio was 1:10 [31]. In these two processes wheat straw was used as the raw material. Isolation of wheat straw organosolv lignin (OSL) was performed under liquor-to-ratio 1:2, followed by addition of sulphuric acid at $\mathrm{pH} 2$. Wheat straw soda lignin (SSL) was precipitated using sulphuric acid following the procedure described by DomínguezRobles et al [31]. Softwood kraft lignin (SKL) was an industrial lignin from a kraft pulp mill (Metsä Fibre, Finland) that produces paper-grade softwood (pine and spruce) pulp. The lignin was precipitated from the black liquor using carbon dioxide followed by acid wash to remove inorganic substances. The lignin isolation protocol was similar as explained earlier by Tomani [32].

\subsection{Characterization of the lignin samples}

The total lignin content was considered to be the sum of Klason lignin and acid soluble lignin. In these determinations, an acid hydrolysis was performed to define the Klason lignin by gravimetric yield, acid soluble lignin from the UV-absorption of the hydrolysate at 215 and $280 \mathrm{~nm}$, and carbohydrates from the hydrolysate using HPAECPAD [33]. Ash content was determined separately from the lignin samples gravimetrically in a muffle furnace. Samples were heated to $800^{\circ} \mathrm{C}$ and maintained at this temperature for 3-6 h until black carbon particles had disappeared. 
Hydroxyl content analyses were determined using a quantitative ${ }^{31} \mathrm{P}$ NMR procedure as published by Granata and Argyropoulos [34]. NMR spectra were acquired using a Bruker $500 \mathrm{MHz}$ spectrometer (Billerica, MA, USA). The NMR parameters used were 1024 scans with pulse delay of $5 \mathrm{~s}, 90^{\circ} \mathrm{C}$ pulse and line boarding of 2 and default base line correction.

The molar mass measurements of the lignin samples were determined by size exclusion chromatography (SEC) with UV detection at $280 \mathrm{~nm}$ as explained elsewhere [35]. Samples were dissolved in $0.1 \mathrm{M} \mathrm{NaOH}$ solution $(1 \mathrm{mg} / \mathrm{ml})$ and filtered $(0.45 \mu \mathrm{m})$. SEC analysis was performed using $0.1 \mathrm{M} \mathrm{NaOH}$ eluent $(\mathrm{pH} 13$, using a flow of $0.5 \mathrm{ml} / \mathrm{min}$ and a temperature of $25^{\circ} \mathrm{C}$ ) and PSS MCX $1000 \& 100000 \AA$ columns. The molar mass distributions (MMD), number average molar mass $\left(M_{n}\right)$, weight average molar mass $\left(\mathrm{M}_{\mathrm{w}}\right)$ and polydispersity (PD) were calculated against polystyrene sulphonate standards (eight standards with a range of $3420-148500 \mathrm{~g} / \mathrm{mol}$ ) and using Waters Empower 3 software (Milford, MA, USA).

\subsection{Preparation of superabsorbent hydrogels films}

For each batch of lignin hydrogels, $3 \mathrm{~g}$ of lignin-containing sample (o.d.) (10\% w/w) were mixed in $21 \mathrm{ml}$ of aqueous $\mathrm{NaOH}(0.5 \mathrm{M})$ or $\mathrm{NH}_{4} \mathrm{OH}(1 \mathrm{M})$ under magnetic stirring for 1 hour at room temperature. Then $6 \mathrm{~g}$ of PMVE/MA (20\% w/w) were then added to this mixture and the solution was mixed again using a spatula due the high viscosity.

The solutions were centrifuged at 3,500 rpm for 15 minutes in order to remove any remaining air bubbles. After this step, the solutions were poured into silicone moulds of $40 \mathrm{~mm}$ diameter and $1 \mathrm{~mm}$ deep. The cast blend was dried for 48 hours at room 
temperature and then cured in oven at $80^{\circ} \mathrm{C}$ for $24 \mathrm{~h}$ to induce crosslinking between PMVE/MA and lignin.

\subsection{Dynamic and equilibrium swelling studies}

For swelling studies, crosslinked samples $\left(c a .0 .5 \mathrm{~cm}^{2}\right)$ of the above formulations were weighed in the dry state $\left(\mathrm{m}_{\mathrm{o}}\right)$ and then swollen in deionized water at room temperature for $24 \mathrm{~h}$. The swelling kinetics was defined by removing the samples from the water at selected time intervals, dried gently with filter paper to eliminate the excess surface water and weighed $\left(\mathrm{m}_{\mathrm{t}}\right)$. Thus, the percentage swelling was calculated by using Equation (1). These studies were done in triplicate to calculate the average value $( \pm$ standard deviation).

$\%$ Swelling $=\left(\frac{\mathrm{m}_{\mathrm{t}}-\mathrm{m}_{\mathrm{o}}}{\mathrm{m}_{\mathrm{o}}}\right) \times 100$

\subsection{Fourier transform infrared spectroscopy (FTIR)}

The lignin and hydrogel samples were analysed using Attenuated Total Reflectance Fourier Transform Infrared Spectroscopy (ATR-IR). The spectra were measured from the samples before and after curing at $80^{\circ} \mathrm{C}$ as well as the lignin samples and the PMVE/MA were recorded using a Spectrum Two ${ }^{\mathrm{TM}}$ instrument (Perkin Elmer, Waltham, MA, USA) by the attenuated total reflectance (ATR) technique. The spectra were recorded from 4000 to $450 \mathrm{~cm}^{-1}$ with a resolution of $4 \mathrm{~cm}^{-1}$ and performing 20 scans.

\subsection{Rheological study}


Hydrogels were swollen in water at room temperature for $24 \mathrm{~h}$ before the rheological measurements were taken using an AR-G2 rheometer (TA Instruments, New Castle, DE, USA) equipped with a $20 \mathrm{~mm}$ parallel plate. Measurement of the storage modulus $\left(\mathrm{G}^{\prime}\right)$ and loss modulus $\left(\mathrm{G}^{\prime \prime}\right)$ were conducted at shear stress range from 0.01 to $1000 \mathrm{~Pa}$ at controlled frequency of $0.1 \mathrm{~Hz}$. The measurements were stopped when both storage modulus and loss modulus began to decrease significantly. For each sample at least three specimens were measured, and the values were averaged.

\subsection{Scanning electron microscopy (SEM)}

Scanning electron microscopy (SEM) of selected hydrogel samples was performed to investigate their morphology. Lignin hydrogels were first placed into deionized water to equilibrium at room temperature. Then, the samples were frozen at $-40^{\circ} \mathrm{C}$ for $24 \mathrm{~h}$ and freeze-dried in a Beta 1-8 LDplus freeze drier (Martin Christ, Osterode am Harz, Germany) under vacuum at $-42^{\circ} \mathrm{C}$ for $48 \mathrm{~h}$. Before SEM observation, specimens of the hydrogels were sputter coated with a thin layer of platinum. SEM analysis was performed with a Zeiss Merlin field emission scanning electron microscope (FE-SEM) with an on-axis in-lens secondary electron detection mode and a chamber secondary electron detection mode.

\subsection{Methylene blue uptake}

Dry hydrogels (weighing between 20 and $30 \mathrm{mg}$ ) were placed in $20 \mathrm{~mL}$ of aqueous solution of $\mathrm{MB}(1 \mathrm{mg} / \mathrm{mL})$ and stirred using an orbital shaker $(90 \mathrm{rpm})$ for $48 \mathrm{~h}$ at room temperature. The MB concentration in the solution was measured by spectrophotometry at $665 \mathrm{~nm}$, using an automated microplate reader (Varioskan Flash, Thermo Scientific, USA). The amount of MB adsorbed by the hydrogel was calculated by using the Equation (2). 
MB Loading Content $=\frac{\left(C_{i}-C_{r}\right) V_{1}}{m_{1}}$

Where $\mathrm{Ci}$ is the initial MB concentration in the solution $(\mathrm{g} / \mathrm{ml}), \mathrm{Cr}$ is the concentration after selected adsorption time $(\mathrm{g} / \mathrm{ml}), \mathrm{V} 1$ is the total volume of the solution $(\mathrm{ml})$ and $\mathrm{m}_{1}$ is the weight of the hydrogel (g o.d.).

The strength of the MB retention was also studied. The selected hydrogels loaded with MB were frozen at $-40^{\circ} \mathrm{C}$ for 24 hours thereafter and further freeze-dried in a Beta $1-8$ LDplus freeze drier (Martin Christ, Osterode am Harz, Germany) under vacuum at $42^{\circ} \mathrm{C}$ for $48 \mathrm{~h}$. Freeze-dried hydrogels were placed in deionized water and the release of MB was determined at different time intervals, using an automated microplate reader (Varioskan Flash, Thermo Scientific, USA) as has been mentioned previously. The cumulative amount of cationic model molecule released from lignin hydrogels was calculated from Equation (3) [36].

Cumulative Amount Released $\%=\frac{\mathrm{M}_{\mathrm{t}}}{\mathrm{M}_{0}} \times 100$

Where $M_{t}$ is the amount of $M B$ released from the lignin hydrogels at time $t$ and $M_{0}$ is he actual amount of MB loaded in these hydrogels.

\section{Results and discussion}

\subsection{Lignin characterization}

The three lignin samples used for the hydrogels synthesis were characterised to establish their chemical composition (Table 1). Determining Klason (KL) lignin and acid-soluble lignin (ASL) content in a sample is the most common method used to define the total lignin content. SKL and OSL presented the highest lignin content, achieving values above 90\%. The impurities present in these samples such as 
carbohydrates and ashes were less than those obtained for the SSL. The ash content was especially high in this latter sample (29.25\%). This high value could be explained by the higher silica (7.3\%) and ash (9.6\%) content in wheat straw [37]. Part of this inorganic material can end up in the lignin precipitate after a soda pulping process [38], while not that much in ethanol-based organosolv treatment, as has been previously reported [30].

\section{Table 1 goes here}

Fig. 1 shows the GPC chromatographic peaks of the isolated lignins and Table 2 shows their molar masses. The lignin molar mass can be different depending on the raw material and the extraction process used [39]. In this study, three different pulping processes were performed, organosolv, soda and kraft processes, using the same feedstock (wheat straw) for the first two processes and softwood for the last one. Organosolv lignin (OSL) had lower molecular mass than soda and kraft lignins (SSL and SKL), which agreed with literature [40]. Organosolv lignins usually has a low molar mass and polydispersity compared to other type of lignins. It indicates that lignin coming from organosolv process is more depolymerised than lignin obtained from alkaline processes such as soda or kraft processes. Also, repolymerisation reactions could be induced during alkaline pulping, increasing the Mw of the samples [41]. All this could explain the results showed in the Table 2 .

Table 2 goes here

Fig. 1 goes here

The functional groups in all the different types of lignins were measured to assess the importance of their reactivity in crosslinking. Both aliphatic and phenolic $\mathrm{OH}$ groups may be involved in the formation of ester linkages with the acids groups from 
polycarboxylic acid. The ${ }^{31} \mathrm{P}$ NMR spectra in Fig. 2 and the calculated values in the Table 3 illustrate the differences between straw and softwood lignins. The aliphatic hydroxyl groups may come from residual carbohydrates or from free hydroxyl groups in the side chain of the phenyl-propane units of the lignin samples. Wheat straw soda lignin (SSL) showed a notable amount of aliphatic $\mathrm{OH}(2.33 \mathrm{mmol} / \mathrm{g})$ followed by SKL $(1.82 \mathrm{mmol} / \mathrm{g})$ and OSL $(1.32 \mathrm{mmol} / \mathrm{g})$. These results are consistent with the previously measured higher content of carbohydrates found for wheat straw soda lignin (Table 1).

The total phenolic OH content was higher for SKL followed by OSL and SSL (4.14, 2.97 and $1.27 \mathrm{mmol} / \mathrm{g}$, respectively). In straw lignins, the number of syringyl units is inherently high due to the fact that these lignins are considered as HGS type lignins. Consequently, three types of $\mathrm{OH}$ groups were found $\left(\mathrm{H}_{\mathrm{OH}}, \mathrm{G}_{\mathrm{OH}}\right.$ and $\left.\mathrm{S}_{\mathrm{OH}}\right)$.

The amount of syringyl units is low by its nature in softwood lignins. Therefore, the obtained number of syringyl units for SKL $(1.81 \mathrm{mmol} / \mathrm{g})$ is due to the condensed phenolic units. This obtained value is slightly higher than the previously reported values for different softwood kraft lignin samples [42].

Guaicyl phenolic groups are the most abundant phenolic groups in softwood lignin. The value for SKL $(2.08 \mathrm{mmol} / \mathrm{g})$ is consistent with the values published for softwood $\mathrm{kraft}$ lignins [42]. The values obtained for OSL and SSL are in line with the results published earlier for similar lignin samples $[43,44]$. The results of the $H$ phenolic groups are in consonance with those found in the literature [40,44]. The lower amount of these $\mathrm{H}$ phenolic groups obtained for SSL when compared to the other wheat straw lignin (OSL) could be due to the alkaline process used in the first one [45].

The carboxylic acid content was higher for SSL sample $(0.88 \mathrm{mmol} / \mathrm{g})$. This value was almost two-fold higher than the values obtained in the other two lignin samples $(0.48$ 
and $0.40 \mathrm{mmol} / \mathrm{g}$ for OSL and SKL, respectively). Additionally, in the ${ }^{31} \mathrm{P} \mathrm{NMR}$ spectrum of the OSL appears a narrow band which is only present in this sample. This band corresponds to the shift of phosphorylated alcohol groups in ethanol (146.3 ppm) [42], and it is due to the residual reagent used in the organosolv pulping process. Although this lignin sample was dried at $60{ }^{\circ} \mathrm{C}$ in the vacuum oven for 48 hours, the ethanol was no removed. This may be because strong physical interactions have been formed as has also been observed earlier in ethanol-based lignin fractionation $[42,46]$.

Table 3 goes here

Fig. 2 goes here

\subsection{Hydrogel synthesis}

Lignin hydrogels were produced using three different lignin samples (OSL, SSL and SKL) and PMVE/MA using a thermal treatment $\left(80^{\circ} \mathrm{C}\right)$ to induce the crosslinking. For comparison, non-crosslinked hydrogels were produced in similar manner without the thermal treatment. Both specimens were placed into deionized water, and the noncrosslinked hydrogels disintegrated, while the cured samples became swollen. This is an evidence that the crosslinked was only formed using the thermal treatment $\left(80^{\circ} \mathrm{C}\right)$.

Some examples of lignin-based hydrogels can be found in the literature $[6,11,13]$. However, one of the novel aspects of the present work is the simplicity of the synthetic procedure. The synthetic step only requires to use a thermal procedure in solid state without using any type of organic solvents or potentially toxic reagents (such as initiators). Additionally, the crosslinking reaction is an esterification reaction and the main sub-product of this reactions is water. Accordingly, the obtained hydrogels can be considered a "green" material as they are prepared using a renewable biopolymer and its 
synthetic procedure can be considered environmental friendly. Finally, due to its simplicity the synthetic step can be consider scalable for industrial production of the lignin-based hydrogels.

\subsection{FTIR analysis}

In order to establish the chemical nature of crosslinking, the hydrogel samples were subjected to FTIR analysis. The obtained spectra were compared with the spectra of the pure polymers and non-crosslinked hydrogels (Fig. 3).

The peak assignment is summarised in Table $4[31,47,48]$. The spectra of PMVE/MA presented a characteristic band at $1704 \mathrm{~cm}^{-1}$, that can be assigned to the acid carbonyl groups. Additionally, the shoulder at $1777 \mathrm{~cm}^{-1}$ indicated the presence of maleic anhydride groups in the PMVE/MA. On the other hand, the spectra of the hydrogels treated at $80^{\circ} \mathrm{C}$ showed two different carbonyl peaks. The first at $c a .1708 \mathrm{~cm}^{-1}$ was assigned to the acid carbonyl groups. The second carbonyl peak at $c a .1773 \mathrm{~cm}^{-1}$ can be attributed to the formation of anhydride groups between adjacent acid groups in the PMVE/MA or between acid groups from the lignin and the PMVE/MA acid groups (Fig. 3). A shift on the $\mathrm{C}=\mathrm{O}$ peak from 1708 to $1735 \mathrm{~cm}^{-1}$ in the FTIR spectra of the crosslinked hydrogels indicates the esterification reaction had occurred [47-49]. However, when the crosslinking degree is very low it is hard to view this absorption band of ester carbonyl. These IR measurement results are consistent with that reported by Zhang et al [47]. To further understand the crosslinking process, Fig. 4 shows the chemical structures and proposed chemical reactions that take place during this process.

Additionally, the spectra of the crosslinked hydrogels showed an increase in the intensity of the bands located at $c a .1185$ and $1071 \mathrm{~cm}^{-1}$ when compared to the noncrosslinked hydrogels (Fig. S1, supporting information). These two bands were 
attributed to $\mathrm{C}-\mathrm{O}-\mathrm{C}$ group, which is also presented in the PMVE/MA polymer. This greater intensity of these bands in the crosslinked hydrogels may be due to the formation of anhydride groups, as mentioned above, but also the formation of ester bonds between $\mathrm{OH}$ groups of lignins and carboxyl group of PMVE/MA.

\section{Fig. 3 goes here}

Table 4 goes here

Fig. 4 goes here

\subsection{Swelling studies}

For swelling studies, the crosslinked hydrogels were placed in deionized water for $24 \mathrm{~h}$, and their water uptake capacity was measured at different time intervals. The percentage swelling ratio was plotted against time (Fig. 5). OSL-NH $4 \mathrm{OH}_{4}$ hydrogels could not be studied since they disintegrated in water solution during the swelling test. These results suggested that the crosslinking degree of these materials was too low to produce a stable hydrogel.

Lignin type and the solvent used to prepare the hydrogels influenced the swelling kinetics of the resulting hydrogels. Lower swelling capacity was observed for the hydrogels prepared using sodium hydroxide as the solvent (13.1, 30.2 and $131.3 \mathrm{~g}$ of water per $1 \mathrm{~g}$ of initial sample, for SSL, SKL and OSL, respectively) when compared to the hydrogels obtained using ammonium hydroxide as base $(54 \mathrm{~g} / \mathrm{g}, 123.3 \mathrm{~g} / \mathrm{g}$ for SSL and SKL, respectively). Thus, it seems clear that the hydrogel samples made with ammonium hydroxide can absorb a higher amount of water compared with the hydrogels prepared using sodium hydroxide. It is well known that the degree of 
swelling decrease at the expense of increasing the crosslink density [50] which was also observed in the present study.

The chemical structure of the lignin molecules also affected the swelling capacities. The lower water intake was observed in the hydrogels prepared using SSL followed by SKL and OSL. These differences could be explained by the different amount of aliphatic $\mathrm{OH}$ groups presented for the three studied lignins (Table 3). The thermal induced crosslinking between PMVE/MA acid groups and the hydroxyl groups of lignin samples is expected to occur via esterification reaction as explained above. Hydroxyl groups coming from lignin could be aliphatic $\mathrm{OH}$ or phenolic $\mathrm{OH}$, however, according to the ${ }^{31}$ P NMR results (Table 3) and the values obtained in the swelling experiments (Fig. 5), aliphatic $\mathrm{OH}$ groups seem to have a stronger influence on this crosslinking mechanism. These results indicate that a greater proportion of the lignin aliphatic $\mathrm{OH}$ may be increasing the degree of crosslinking and, thus, there is less free volume to accommodate water.

The swelling study revealed that these lignin hydrogels were able to absorb a larger amount of water (ranged from 13.1 to $131.3 \mathrm{~g}$ of water per $1 \mathrm{~g}$ of initial sample) compared to other hydrogels found in the literature made also from PMVE/MA and Polyethylene glycol (PEG) (22.50 g/g) [17]. Synthetic hydrogel composed of poly (ethylene glycol) (PEG)/poly ( $\mathrm{N}$-isopropylacrylamide-co-acrylamido-2-methylpropyl sulphonic acid) presented a water intake values around $60 \mathrm{~g} / \mathrm{g}$. Moreover, the same hydrogel was able to absorb about $200 \mathrm{~g} / \mathrm{g}$ when placed within an electric field [51]. Additionally, the great swelling capacities of these lignin-based hydrogels make them appealing materials for biological applications, such as wound dressing. The higher water content would allow vapour and oxygen transmission to the wounds [52]. Also, in the treatment of emergency burns hydrogels could be very effective due to their cooling 
and hydrating effect [53]. Indeed, there are already some materials for this type of application, such as Burnshield hydrogel burn dressing, Burnshield (Pty) Ltd [54].

\section{Fig. 5 goes here}

\subsection{Mechanical properties}

The rheological properties of the hydrogels were measured to establish the elastic properties of these materials, such as gel strength. Dynamical mechanical analysis of the swollen lignin hydrogels was performed by changing the oscillatory stress from 0.01 to $1000 \mathrm{~Pa}$ at a constant frequency $(1 \mathrm{~Hz})$. The analysis provided information about the storage modulus $\left(\mathrm{G}^{\prime}\right)$, the loss modulus ( $\left.\mathrm{G}^{\prime \prime}\right)$ and the phase angle (Table 5).

The phase angle shows the rheological behaviour of the analysed material, a phase angle of $0^{\circ}$ indicates a perfectly elastic material. On the other hand, a phase angle of $90^{\circ}$ means a perfectly viscous material. Furthermore, a larger value of $G^{\prime}$ when compared to G” indicates that the analysed material has pronounced elastic properties [55].

Both parameters, G' and G", varied according to the lignin type and the solvent used to perform the hydrogels. Storage modulus (G') was higher for the samples prepared using $\mathrm{NaOH}$ solutions when compared to the samples prepared using $\mathrm{NH}_{4} \mathrm{OH}$ solutions. Additionally, wheat straw soda lignin (SSL) showed improved mechanical properties. The results showed a clear tendency indicating that hydrogels able to absorb a higher amount of water showed lower storage modulus. As previously described, the degree of swelling is inversely related to the crosslink density [50]. Therefore, this fact illustrates the contribution of the chemical crosslinking to the viscoelastic properties. 
For all the samples it was found that the storage modulus was higher than the loss modulus $\left(G^{\prime} / G^{\prime \prime}>1\right)$, exhibiting the formation of an elastic network. These results are also supported by the obtained values for the phase angle (lower than $45^{\circ}$ ).

\section{Table 5 goes here}

\subsection{Characterization of synthesized hydrogels by SEM}

SEM characterizations of freeze-dried lignin-based hydrogels are shown in Fig. 6. It can be observed that all the samples showed a highly porous structure including different pore size distributions. Both large and small pores are appreciable in all the materials, indicating an inhomogeneous structure. It seems that the samples SSL-NaOH, SSL$\mathrm{NH}_{4} \mathrm{OH}$ and $\mathrm{SKL}-\mathrm{NaOH}$ showed a more homogeneous pore size distribution. Furthermore, these three hydrogels presented higher storage modulus values when compared to the other two samples. These results can be correlated with the swelling capacity as SSL-NaOH, SSL-NH${ }_{4} \mathrm{OH}$ and SKL-NaOH hydrogels showed the lowest swelling capacities. In contrast, $\mathrm{OSL}-\mathrm{NaOH}$ and $\mathrm{SKL}-\mathrm{NH}_{4} \mathrm{OH}$ showed a more irregular structure consistent with a higher water uptake. As before, these SEM micrographs are in agreement with the results described previously.

\section{Fig. 6 goes here}

\section{7. $M B$ adsorption}

Lignin-based hydrogels presented high negative charge due to the numerous carboxylic acid groups present in the samples, as was illustrated by the FTIR spectra. In order to take advantage of this property the absorption of a cationic dye was evaluated. Methylene blue (MB) was selected as a cationic model molecule as it is the most commonly used substance for dying cotton, wood and silk. This compound has been 
proven to be very harmful for human and animals [56,57] causing severe and permanent eye injury. MB is also associated with adverse health effects if inhaled or swallowed, such as breath shortness, nausea, vomiting or even mental confusion. Then, this compound is a good model as it should be removed from the effluents [56,57].

Fig. 7(a) showed the MB absorption of the lignin-based hydrogels. It is noticeable that the hydrogels showed high affinity for $\mathrm{MB}$ as some of them $\left(\mathrm{SSL}-\mathrm{NH}_{4} \mathrm{OH}\right.$ and SKL$\mathrm{NH}_{4} \mathrm{OH}$ hydrogel samples) were able to absorb $>800 \mathrm{mg}$ per $\mathrm{g}$ of dry hydrogel. The hydrogels that present higher MB absorption were the ones that were prepared using an aqueous ammonium hydroxide solution rather than an aqueous sodium hydroxide solution. Interestingly OSL-NaOH hydrogels presented the highest maximum water adsorption (Fig. 4) but not the highest MB uptake. Consequently, the main factor that could have an influence on the MB adsorption is the alkali type used to prepare the hydrogels, although the nature of the lignin also showed a minimal influence on the MB adsorption.

These adsorption values of MB (ranged from 460 to $840 \mathrm{mg} / \mathrm{g}$ dry sample) of these lignin hydrogels are similar or even much higher to those obtained with different commercial activated carbons (CACs) or coals found in the literature such as, CAC (Merck) (980.3 mg/g); AC produced from New Zealand coal (588.43 mg/g); bituminous coal $(323.68 \mathrm{mg} / \mathrm{g})$; or charcoal $(62.7 \mathrm{mg} / \mathrm{g})$ [57]. However, the use of the AC is restricted due to its relatively high cost [57].

During the recent years the potential of bio-renewable polymers to be included in hydrogels for MB removal from waste waters has been evaluated in several works. [27,58-60]. When the MB uptake studies were done in similar conditions to the PMVE/MA-lignin hydrogels the absorption capacities were similar $(800-1000 \mathrm{mg} / \mathrm{g}$ ) 
[58,59]. Additionally, PMVE/MA-lignin hydrogels presented higher MB uptake than the hydrogels described by Luo et al. (15 mg/g) [60] and Cheng et al. (95.6 - 148.8 $\mathrm{mg} / \mathrm{g}$ ) [27]. Moreover, one the main advantage of the present system over the materials described in the literature is that the synthesis of the lignin-hydrogel does not require the use of any toxic solvents/reagents and it is simple and can be easily scalable. The majority of the hydrogels described in the literature require the use of complex synthetic procedures and some of them use highly toxic reagents such as acrylamides [58-60]. Therefore, the synthesised hydrogels could be an interesting alternative from the removal of cationic dyes from waste water as these materials showed a high efficiency and required little processing.

After evaluating the MB uptake capacity of the hydrogels, the next step was to study MB retention. It is important to show that the MB was strongly bound to the hydrogel backbone of these materials. Firstly, the swollen hydrogels loaded with MB were placed directly into deionized water. However, no release of MB could be observed within 24 hours (or whichever time you followed this). Therefore, the hydrogels loaded with MB were freeze-dried and placed into deionized water and the release of MB was followed as function of time.

Fig. 7(b) shows the MB release curves from the different hydrogels. All lignin hydrogels showed a strong MB retention capacity as after several days less than $0.5 \%$ of the initial loading was released. Additionally, it can be observed SSL hydrogels showed stronger MB retention as the release was significantly smaller. This may be due to the higher carboxyl group content in the SSL sample yielding to hydrogels with higher concentration of negatively charged groups when compared to the other two ligninbased hydrogels $[61,62]$. These carboxylic acid groups present a larger electronegativiy 
$(\mathrm{pKa}=4-5)$, compared to phenolic $\mathrm{OH}$ groups $(\mathrm{pKa}=10)$, and the aliphatic $\mathrm{OH}$ groups $(\mathrm{pKa}=16-18)$.

The obtained percentage of MB released from the hydrogels ranged from 0.06 to 0.35 $\%$. These results were lower than those obtained with other synthetic hydrogels described in the literature (ranged from 0.44 to $35.22 \%$ ) [51]. These results could be explained by the entrapment of the MB molecules within the network structure of the hydrogels and by the strong binding interactions between the MB molecules due to the negative charge of the hydrogels.

Fig. 7 goes here

\section{Conclusions}

Renewable and biocompatible hydrogels for removing cationic dyes from waste water were successfully synthesised and characterised by crosslinking different technical lignins with PMVE/MA via ester linkages. The hydrogels were obtained using a green process as no organic solvents or potentially toxic reagents were used and the main reaction by product was water. Hydrogel characterization indicated that the base $\left(\mathrm{NaOH}\right.$ or $\left.\mathrm{NH}_{4} \mathrm{OH}\right)$ and lignin structure in the production of these materials were two key aspects for the material properties. Lignin hydrogels synthesized using ammonium hydroxide as solvent were able to absorb a larger amount of water and MB when compared to the other hydrogels. In addition, the hydrogels made with SSL showed stronger MB retention. This lignin sample also improved the mechanical properties. 
The water absorption capacity was very high when compared to hydrogels presented in literature, and therefore suggest that these products could be applied as super-absorbents material. The MB adsorption results obtained for the lignin hydrogels were comparable to the ones obtained for activated charcoals. The amount of MB released was less than $1 \%$ for all the hydrogels. Minor differences were observed between the different ligninbased hydrogels. Thus, these novel and environmental friendly hydrogels may lead to some potential promising application removing harmful substance in effluents.

According to all the measured parameters, it can be concluded that the SSL- $\mathrm{NH}_{4} \mathrm{OH}$ hydrogel are the best hydrogels for MB removal. As they presented good mechanical properties and MB uptake. Furthermore, this specimen presented the higher strength of MB retention.

\section{Acknowledgement}

The authors wish to acknowledge M.Sc. Harri Setälä, M.Sc. Kari Kammiovirta, M.Sc. Atte Mikkelson, M.Sc. Pia Willberg-Keyriläinen and M.Sc. Martina Lille for skilful expertise in lignin analytics and polymers knowledge. The authors would also like to thank Spain's DGICyT, MICINN for funding part of this research within the framework of the project CTQ2013-46804-C2-2-R.

\section{References}

[1] A. Demirbas, Biorefineries: For Biomass Upgrading Facilities, Springer, Dordrecht, New York, 2010. 
[2] J. Ralph, K. Lundquist, G. Brunow, F. Lu, H. Kim, P.F. Schatz, J.M. Marita, R.D. Hatfield, S.A. Ralph, J.H. Christensen, W. Boerjan, Lignins: natural polymers from oxidative coupling of 4-hydroxyphenylpropanoids, Phytochem. Rev. 3 (2004) 29-60.

[3] W. Boerjan, J. Ralph, M. Baucher, Lignin biosynthesis, Annu. Rev. Plant Biol. 54 (2003) 519-546.

[4] A.J. Ragauskas, G.T. Beckham, M.J. Biddy, R. Chandra, F. Chen, M.F. Davis, B.H. Davison, R.A. Dixon, P. Gilna, M. Keller, P. Langan, A.K. Naskar, J.N. Saddler, T.J. Tschaplinski, G.A. Tuskan, C.E. Wyman, Lignin valorization: improving lignin processing in the biorefinery, Science 344 (2014) 1246843. DOI: 10.1126/science. 1246843

[5] G. Gellerstedt, Softwood kraft lignin: Raw material for the future, Ind. Crops Prod. 77 (2015) 845-854.

[6] V.K. Thakur, M.K. Thakur, Recent advances in green hydrogels from lignin: a review, Int. J. Biol. Macromol. 72 (2015) 834-847.

[7] V.K. Thakur, M.K. Thakur, P. Raghavan, M. R. Kessler, Progress in Green Polymer Composites from Lignin for Multifunctional Applications: A Review, ACS Sustain. Chem. Eng. 2 (2014) 1072-1092

[8] J. Domínguez-Robles, R. Sánchez, P. Díaz-Carrasco, E. Espinosa, M.T. GarcíaDomínguez, A. Rodríguez, Isolation and characterization of lignins from wheat straw:Application as binder in lithium batteries, Int. J. Biol. Macromol. 104 (2017a) 909-918. 
[9] D. Stewart, Lignin as a base material for materials applications: Chemistry, application and economics. Ind. Crops Prod. 27 (2008) 202-207.

[10] M.N.S. Kumar, A.K. Mohanty, L. Erickson, M. Misra, Lignin and its applications with polymers, J. Biobased Mater. Bioeng. 3 (2009) 1-24.

[11] A.J. Peñaranda, M. Sabino, Effect of the presence of lignin or peat in IPN hydrogels on the sorption of heavy metals, Polym. Bull. 65 (2010) 495-508.

[12] L.I. Grishechko, G. Amaral-Labat, A. Szczurek, V. Fierro, B.N. Kuznetsov, A. Pizzi, A. Celzard, New tannin-lignin aerogels, Ind. Crops Prod. 41 (2013) 347- 355.

[13] Z. Peng, F. Cheng, Synthesis and Properties of Lignin-Based Polyurethane Hydrogels, Int. J. Polym. Mater. 60 (2011) 674-683.

[14] D.M. García, J.L. Escobar, N. Bada, J. Casquero, E. Hernáez, I. Katime, Synthesis and characterization of poly(methacrylic acid) hydrogels for metoclopramide delivery, Eur. Polym. J. 40 (2004)1637-1643.

[15] T.R.R. Singh, M.J. Garland, K. Migalska, E.C. Salvador, R. Shaikh, H.O. McCarthy, A.D. Woolfson, R.F. Donnelly, Influence of a Pore-Forming Agent on Swelling, Network Parameters, and Permeability of Poly(ethylene glycol)-Crosslinked Poly(methyl vinyl ether-co-maleic acid) Hydrogels: Application in Transdermal Delivery Systems, J. Appl. Polym. Sci. 125 (2012) 2680-2694

[16] N.A. Peppas, J.Z. Hilt, A. Khademhosseini, R. Langer, Hydrogels in Biology and Medicine: From Molecular Principles to Bionanotechnology, Adv. Mater. 18 (2006) 1345-1360. 
[17] E. Larrañeta, R.E.M. Lutton, A.J. Brady, E.M. Vicente-Pérez, A.D. Woolfson, R.R.S. Thakur, R.F. Donnelly, Microwave-Assisted Preparation of Hydrogel-Forming Microneedle Arrays for Transdermal Drug Delivery Applications, Macromol. Mater. Eng. 300 (2015) 586-595.

[18] A. Kumar, K.M. Rao, S.S. Han, Synthesis of mechanically stiff and bioactive hybrid hydrogels for bone tissue engineering applications, Chem. Eng. J. 317 (2017) $119-131$.

[19] B. Singh, S. Sharma, A. Dhiman, Acacia gum polysaccharide based hydrogel wound dressings: Synthesis, characterization, drug delivery and biomedical properties, Carbohyd. Polym. 165 (2017) 294-303.

[20] K. Hemvichian, A. Chanthawong, P. Suwanmala, Synthesis and characterization of superabsorbent polymer prepared by radiation-induced graft copolymerization of acrylamide onto carboxymethyl cellulose for controlled release of agrochemicals, Radiat. Phys. Chem. 103 (2014) 167-171.

[21] R. Bhattacharyya, S.K. Ray, B. Mandal, A systematic method of synthesizing composite superabsorbent hydrogels from crosslink copolymer for removal of textile dyes from water, J. Indust. Eng. Chem. 19 (2013) 1191-1203.

[22] S. Thakur, P.P. Govender, M.A. Mamo, S. Tamulevicius, Y.K. Mishra, V.K. Thakur, Progress in lignin hydrogels and nanocomposites for water purification: Future perspectives, Vacuum 146 (2017) 342-355.

[23] K. Ravikumar, B. Deebika, K. Balu, Decolourization of aqueous dye solutions by a novel adsorbent: Application of statistical designs and surface plots for the optimization and regression analysis, J. Hazard. Mater. 122 (2005) 75-83. 
[24] D. Xu, S. Hein, L.S. Loo, K. Wang, Modified Chitosan Hydrogels for the Removal of Acid Dyes at High pH: Modification and Regeneration, Ind. Eng. Chem. Res. 50 (2011) 6343-6346.

[25] X. Dou, P. Li, D. Zhang, C.L. Feng, C2-symmetric benzene-based hydrogels with unique layered structures for controllable organic dye adsorption, Soft Matter 8 (2012) $3231-3238$.

[26] N.M. Mahmoodi, F. Najafi, S. Khorramfar, F. Amini, M. Arami, Synthesis, characterization and dye removal ability of high capacity polymeric adsorbent: Polyaminoimide homopolymer, J. Hazard. Mater. 198 (2011) 87-94.

[27] H. Cheng, Q. Feng, C. Liao, Y. Liu, D. Wu, Q. Wang, Removal of MB with Hemicellulose/Clay Hybrid Hydrogels, Chinese J. Polym. Sci. 34 (2016) 709-719.

[28] S.S. Moghaddam, M.R.A. Moghaddama, M.Arami, Coagulation/flocculation process for dye removal using sludge from water treatment plant: Optimization through response surface methodology, J. Hazard. Mater. 175 (2010) 651-657.

[29] T. Robinson, G. McMullan, R. Marchant, P. Nigam, Remediation of dyes in textile effluent: a critical review on current treatment technologies with a proposed alternative, Bioresour. Technol. 77 (2001) 247-255.

[30] W.J.J. Huijgen, G. Telysheva, A. Arshanitsa, R.J.A. Gosselink, P.J. de Wild, Characteristics of wheat straw lignins from ethanol-based organosolv treatment, Ind. Crops Prod. 59 (2014) 85-95. http://dx.doi.org/10.1016/j.indcrop.2014.05.003 
[31] J. Domínguez-Robles, R. Sánchez, E. Espinosa, D. Savy, P. Mazzei, A. Piccolo, A. Rodríguez, Isolation and Characterization of Gramineae and Fabaceae Soda Lignins, Int. J. Mol. Sci. 18 (2017b) 327. DOI:10.3390/ijms18020327

[32] P. Tomani, The lignoboost process, Cellul. Chem. Technol. 44 (2010) 53-58.

[33] M. Tenkanen, M. Siika-Aho, An alpha-glucuronidase of Schizophyllum commune acting on polymeric xylan, J. Biotechnol. 78 (200) 149-161.

[34] A. Granata, D.S. Argyropoulos, 2-Chloro-4,4,5,5-tetramethyl-1,3,2dioxaphospholane, a Reagent for the Accurate Determination of the Uncondensed and Condensed Phenolic Moieties in Lignins, J. Agric. Food Chem. 43 (1995) 1538-1544.

[35] S. Baumberger, A. Abaecherli, M. Fasching, G. Gellerstedt, R. Gosselink, B. Hortling, J. Li, B. Saake, E. de Jong, Molar mass determination of lignins by sizeexclusion chromatography: towards standardisation of the method, Holzforschung, 61 (2007) 459-468.

[36] J.K. Li, N. Wang, X.S.S. Wu, Poly(vinyl alcohol) nanoparticles prepared by freezing-thawing process for protein/peptide drug delivery, J. Control. Release 56 (1998) 117-126.

[37] X. Pan, Y. Sano, Fractionation of wheat straw by atmospheric acetic acid process, Bioresource Technol, 96 (2005) 1256-1263.

[38] J. Domínguez-Robles, E. Espinosa, D. Savy, A. Rosal, A. Rodríguez, Biorefinery Process Combining Specel ${ }^{\circledR}$ Process and Selective Lignin Precipitation using Mineral Acids, BioResources 11 (2016) 7061-7077. 
[39] L.A. Manjarrez, L. Ballinas, A. Celzard, V. Fierro, V. Muñoz, A. Camacho,

Biopolymer-based nanocomposites: effect of lignin acetylation in cellulose triacetate

films, Sci. Technol. Adv. Mater. 12 (2011) 045006. DOI: 10.1088/1468-

$6996 / 12 / 4 / 045006$

[40] R.J.A. Gosselink, J.E.G. van Dam, E. de Jong, E.L. Scott, J.P.M. Sanders, J. Jiebing Li, G. Gellerstedt, Fractionation, analysis, and PCA modeling of properties of four technical lignins for prediction of their application potential in binders, Holzforschung 64 (2010) 192-200.

[41] A. Tejado, C. Peña, J. Labidi, J.M. Echeverria, I. Mondragón, Physico-chemical characterization of lignin from different sources for use in phenol-formaldehyde resin synthesis, Bioresource Technol. 98 (2007) 1655-1663.

[42] A.S. Jääskeläinen, T. Liitiä, A. Mikkelson, T. Tamminen, Aqueous organic solvent fractionation as means to improve lignin homogeneity and purity, Ind. Crops Prod. 103 (2017) 51-58.

[43] B. Ahvazi, O. Wojciechowicz, T.-M. Ton-That, J. Hawari, Preparation of lignopolyols from wheat straw soda lignin, J. Agric. Food Chem. 59 (2011) 1050510516.

[44] F. Monteil-Rivera, M. Phuong, M. Ye, A. Halasz, J. Hawari, Isolation and characterization of herbaceous lignins for applications in biomaterials, Ind. Crops Prod. $41(2013) 356-364$.

[45] C. Crestini, D.S. Argyropoulos, Structural analysis of wheat straw lignin by quantitative ${ }^{31} \mathrm{P}$ and $2 \mathrm{D}$ NMR spectroscopy. The occurrence of ester bonds and $\alpha-\mathrm{O}-4$ substructures, J. Agric. Food Chem. 45 (1997) 1212-1219. 
[46] J. Domínguez-Robles, T. Tamminen, T. Liitiä, M.S. Peresin, A. Rodríguez, A.-S. Jääskeläinen, Aqueous acetone fractionation of kraft, organosolv and soda lignins, Int. J. Biol. Macromol. (2017c). In press, accepted manuscript.

[47] T. Zhang, J. Chen, Q. Zhang, J. Dou, N. Gu, Poly(ethylene glycol)-cross linked poly(methyl vinyl ether-co-maleic acid)hydrogels for three-dimensional human ovarian cancer cell culture, Colloids Surf. A Physicochem. Eng. Asp. 422 (2013) 81-89.

[48] T.R.R. Singh, P.A. McCarron, A.D. Woolfson, R.F. Donnelly, Investigation of swelling and network parameters of poly(ethylene glycol)-crosslinked poly (methyl vinyl ether-co-maleic acid) hydrogels, Eur. Polym. J. 45 (2009) 1239-1249.

[49] E. Larrañeta, M. Henry, N.J. Irwin, J.Trotter, A.A. Perminova, R.F. Donnelly, Synthesis and characterization of hyaluronic acid hydrogels crosslinked using a solventfree process for potential biomedical applications, Carbohydr. Polym. In Press.

[50] H. Omidian, S. Hasherni, F. Askari, S. Nafisi, Swelling and Crosslink Density Measurements for Hydrogels, Iranian Polym. J. 3 (1994) 115-119.

[51] A.K. Saikia, S. Aggarwal, U.K. Mandal, Electrically induced swelling and MB release behaviour of poly ( $\mathrm{N}$-isopropylacrylamide-co-acrylamido- 2-methylpropyl sulphonic acid) hydrogels, Colloid Polym. Sci. 293 (2015) 3533-3544. DOI $10.1007 / \mathrm{s} 00396-015-3719-0$

[52] E. Caló, V.V. Khutoryanskiy, Biomedical applications of hydrogels: A review of patents and commercial products, Eur. Polym. J. 65 (2015) 252-267.

[53] E. Osti, F. Osti, Treatment of cutaneous burns with burnshield (hydrogel) and a semi-permeable adhesive film, Ann. Burns Fire Dis. 17 (2004) 137-141. 
[54] Burnshield Emergency Burncare website. <www.burnshield.com> [accessed July 2017].

[55] K. Hyun, M. Wilhelm, C. Klein, K.S. Cho, J.G. Nam, K.H. Ahn, S.J. Lee, R. H. Ewoldt, G. H. McKinley, A review of nonlinear oscillatory shear tests: Analysis and application of large amplitude oscillatory shear (LAOS), Prog. Polym. Sci. 36 (2011) $1697-1753$.

[56] I.A.W. Tan, A.L. Ahmad, B.H. Hameed, Adsorption of basic dye on high-surfacearea activated carbon prepared from coconut husk: equilibrium, kinetic and thermodynamic studies, J. Hazard. Mater. 154 (2008) 337-346.

[57] M. Rafatullah, O. Sulaiman, R. Hashim, A. Ahmad, Adsorption of MB on low-cost adsorbents: A review, J. Hazard. Mater. 177 (2010) 70-80.

[58] C. Yu, F. Wang, C. Zhang, S. Fu, L.A. Lucia, The synthesis and absorption dynamics of a lignin-based hydrogel for remediation of cationic dye-contaminated effluent, React. Funct. Polym. 106 (2016) 137-142.

[59] X. Song, F. Chen, S. Liu, A lignin-containing hemicellulose-based hydrogel and its adsorption behaviour, BioResources 11 (2016) 6378-6392.

[60] H. Luo, S. Ren, Y. Ma, G. Fang, G. Jiang, Preparation and properties of kraft lignin-N-isopropyl acrylamide hydrogel, BioResources 10 (2015) 3507-3519.

[61] H. Bian, L. Chen, H. Dai, J.Y. Zhu, Integrated production of lignin containing cellulose nanocrystals (LCNC) and nanofibrils (LCNF) using an easily recyclable dicarboxylic acid, Carbohyd. Polym. 167 (2017) 167-176. 
[62] J. Durruty, T. Mattsson, H. Theliander, Local filtration properties of Kraft lignin:

The influence of residual xylan, Sep. Purif. Technol. 179 (2017) 455-466. 
Table 1. Chemical composition of the lignin samples.

\begin{tabular}{ccccc}
\hline \multirow{2}{*}{ Sample } & Klason lignin & $\begin{array}{c}\text { Acid soluble } \\
\text { lignin }\end{array}$ & Carbohydrates & Ash \\
\cline { 2 - 5 } & \multicolumn{4}{c}{$(\%$ of o.d.) } \\
\hline OSL & 91.4 & 2.4 & 1.2 & 0.7 \\
SSL & 64.9 & 3.9 & 2.8 & 29.3 \\
SKL & 96.0 & 2.9 & 1.3 & 2.2 \\
\hline
\end{tabular}


Table 2. Number average $\left(M_{n}\right)$ and weight average $\left(M_{w}\right)$ molecular weights and polydispersity (PD) of the lignin samples.

\begin{tabular}{llll}
\hline Samples & $\mathbf{M}_{\mathbf{n}}(\mathbf{g} / \mathbf{m o l})$ & $\mathbf{M}_{\mathbf{w}}(\mathbf{g} / \mathbf{m o l})$ & PD \\
\hline OSL & 1490 & 2520 & 1.7 \\
SSL & 1970 & 4170 & 2.1 \\
SKL & 2270 & 5360 & 2.4 \\
\hline
\end{tabular}


Table 3. Number of aliphatic and phenolic hydroxyl groups and carboxylic acids in selected samples. Cond. $\mathrm{PhOH}=$ free phenols in condensed guaiacyl units; $\mathrm{G}-\mathrm{PhOH}=$ free phenols in guaiacylic structures; $p-\mathrm{PhOH}=$ free phenols in para-hydroxyphenyl structures and $\mathrm{COOH}=$ carboxylic acids.

\begin{tabular}{ccccccc}
\hline Samples & $\begin{array}{c}\text { Aliphatic } \\
\text { OH } \\
(\mathbf{m m o l} / \mathbf{g})\end{array}$ & $\begin{array}{c}\text { Total } \\
\text { PhOH } \\
(\mathbf{m m o l} / \mathbf{g})\end{array}$ & $\begin{array}{c}\text { Cond. } \\
\mathbf{P h O H} \\
(\mathbf{m m o l} / \mathbf{g})\end{array}$ & $\begin{array}{c}\text { G-PhOH } \\
(\mathbf{m m o l} / \mathbf{g})\end{array}$ & $\begin{array}{c}\boldsymbol{p} \text {-PhOH } \\
(\mathbf{m m o l} / \mathbf{g})\end{array}$ & $\begin{array}{c}\text { COOH } \\
(\mathbf{m m o l} / \mathbf{g})\end{array}$ \\
\hline OSL & 1.32 & 2.97 & 1.42 & 1.06 & 0.49 & 0.48 \\
SSL & 2.33 & 1.27 & 0.47 & 0.54 & 0.25 & 0.88 \\
SKL & 1.82 & 4.14 & 1.81 & 2.08 & 0.24 & 0.40 \\
\hline
\end{tabular}


Table 4. FTIR band assignments of selected bands from PMVE/MA, lignin and crosslinked hydrogels.

\begin{tabular}{ccc}
$\begin{array}{c}\text { Wavenumber } \\
\left(\mathbf{c m}^{-\mathbf{1}}\right)\end{array}$ & Origin & Assignment \\
\hline $\mathbf{1 7 7 3}$ & Hydrogels & COOR in anhydrides \\
$\mathbf{1 7 0 4}$ & PMVE/MA & C $=$ O stretch in carboxylic acid \\
$\mathbf{1 7 7 7}$ & PMVE/MA & COOR in anhydrides \\
$\mathbf{1 5 9 6}$ & Lignin samples & Aromatic \\
$\mathbf{1 5 1 0}$ & Lignin samples & Aromatic \\
\hline
\end{tabular}


Table 5. Viscoelastic parameters of the lignin-based hydrogels.

\begin{tabular}{ccccc}
\hline Samples & $\begin{array}{c}\text { Storage modulus } \\
\text { G' }(\mathbf{P a})\end{array}$ & $\begin{array}{c}\text { Loss modulus } \\
\mathbf{G} \boldsymbol{\prime}^{\prime}(\mathbf{P a})\end{array}$ & $\begin{array}{c}\text { Phase angle } \\
\left({ }^{\circ}\right)\end{array}$ & $\begin{array}{c}\text { Max. oscillation stress } \\
(\mathbf{P a})\end{array}$ \\
\hline SSL-NaOH & $9334.4( \pm 294.6)$ & $953.1( \pm 105.5)$ & $5.8( \pm 0.6)$ & $15.7( \pm 0.0)-24.9( \pm 0.0)$ \\
SKL-NaOH & $2169.1( \pm 114.6)$ & $338.7( \pm 42.3)$ & $8.9( \pm 1.2)$ & $6.0( \pm 0.0)-9.5( \pm 0.0)$ \\
OSL-NaOH & $1023.7( \pm 45.1)$ & $191.1( \pm 32.2)$ & $10.9( \pm 1.7)$ & $2.3( \pm 0.0)-3.6( \pm 0.0)$ \\
SSL-NH4 & & & $12.2( \pm 0.9)$ & $2.4( \pm 0.0)-3.8( \pm 0.0)$ \\
SKL-NH & $2880.2( \pm 106.1)$ & $620.5( \pm 33.7)$ & & $2.1( \pm 0.0)-3.3( \pm 0.0)$ \\
\hline
\end{tabular}




\section{Figure captions}

Fig. 1. Molar mass distribution of isolated lignin samples.

Fig. 2. ${ }^{31} \mathrm{P}$ NMR spectra of isolated lignin samples.

Fig. 3. FTIR-ATR spectra of non-crosslinked (NC), crosslinked hydrogels (oven) using $\mathrm{NH}_{4} \mathrm{OH}$ and $\mathrm{NaOH}$, and the reference materials used and PMVE/MA and lignin samples. Hydrogels made from OSL (A), SSL (B) and SKL (C).

Fig. 4. Chemical structures and proposed chemical reactions taking place during the crosslinking process.

Fig. 5. Swelling kinetics for the studied lignin-based hydrogels in deionized water.

Fig. 6. SEM micrographs lignin-based hydrogels prepared from aqueous sodium hydroxide $(0.5 \mathrm{M})$ blend of $20 \%$ w/w PMVE/MA containing (A) $10 \%$ of SSL, (B) $10 \%$ of SKL and (C) $10 \%$ of OSL. The other micrographs correspond to lignin-based hydrogels prepared from aqueous ammonium hydroxide $(1 \mathrm{M})$ blend of $20 \% \mathrm{w} / \mathrm{w}$ PMVE/MA containing (D) 10\% of SSL and (E and E') 10\% of SKL.

Fig. 7. Absorption (a) and Release (b) of MB from lignin-based hydrogels. 
International Journal of Biological Macromolecules. Domínguez-Robles et al., 2018.

Fig. 1

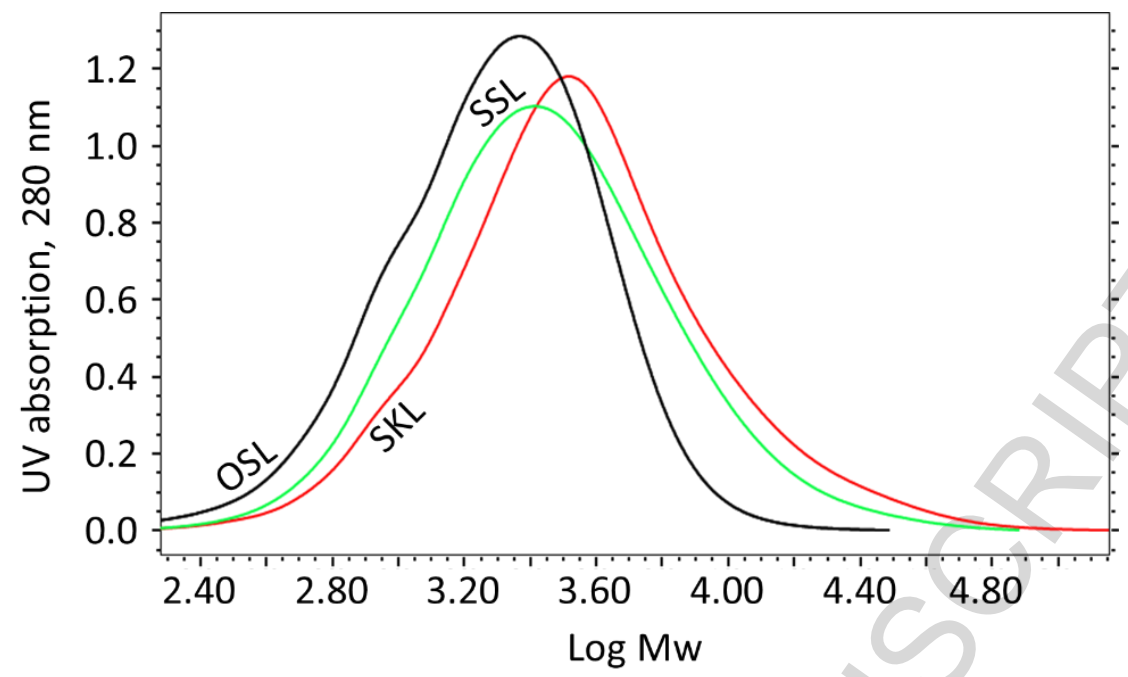


International Journal of Biological Macromolecules. Domínguez-Robles et al., 2018.

Fig. 2

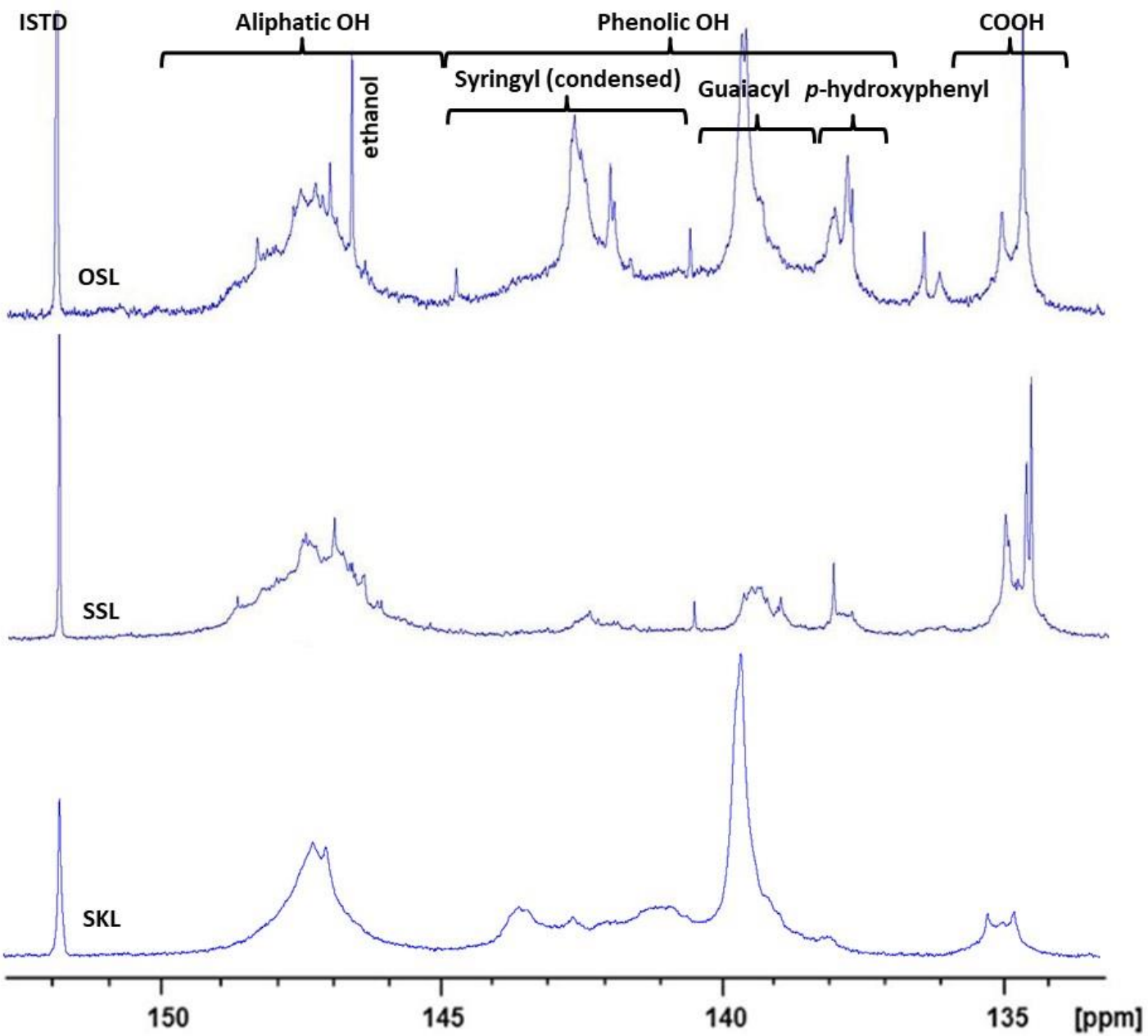


International Journal of Biological Macromolecules. Domínguez-Robles et al., 2018.

Fig. 3
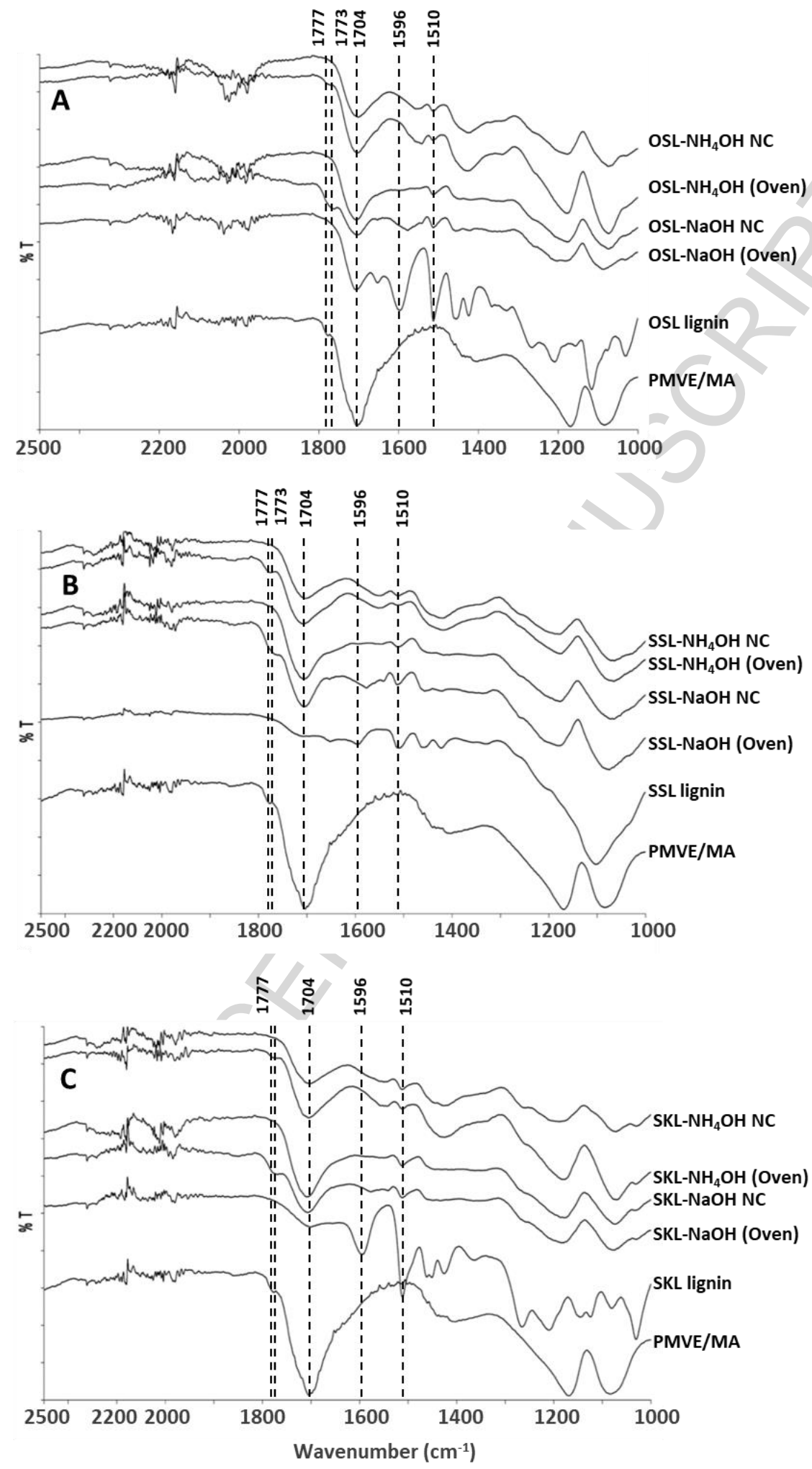
International Journal of Biological Macromolecules. Domínguez-Robles et al., 2018.

Fig. 4

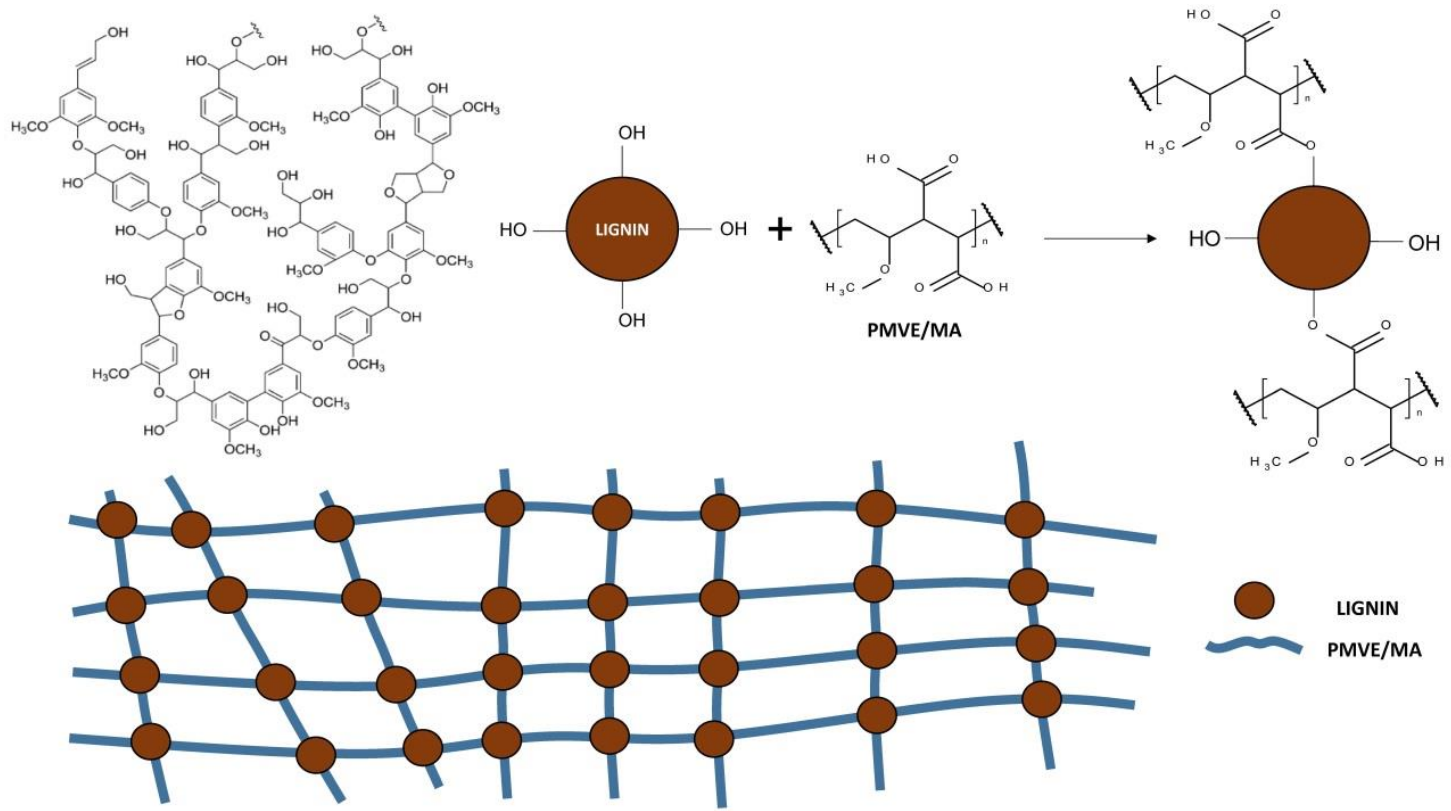


International Journal of Biological Macromolecules. Domínguez-Robles et al., 2018.

Fig. 5

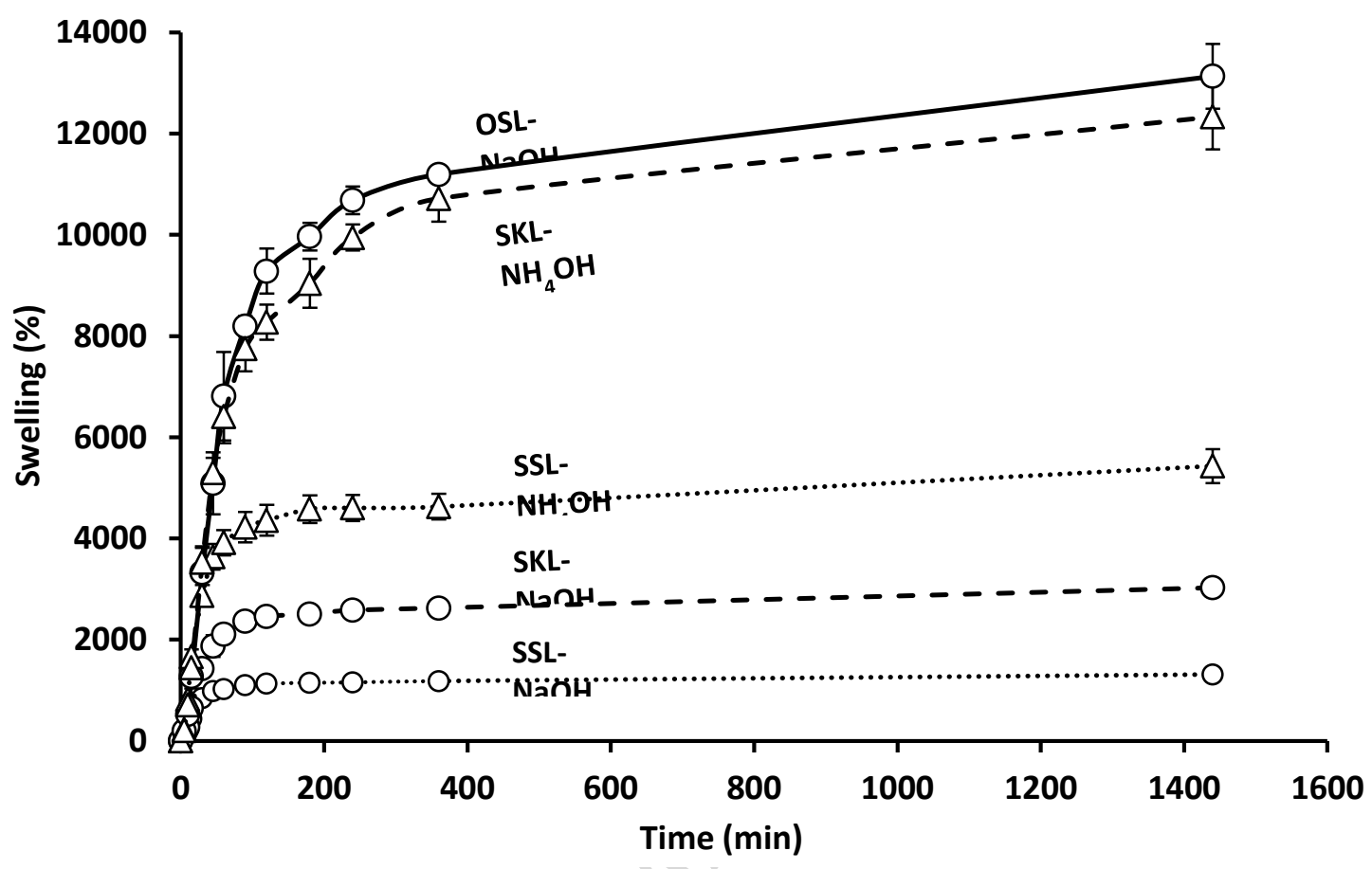


International Journal of Biological Macromolecules. Domínguez-Robles et al., 2018.

Fig. 6

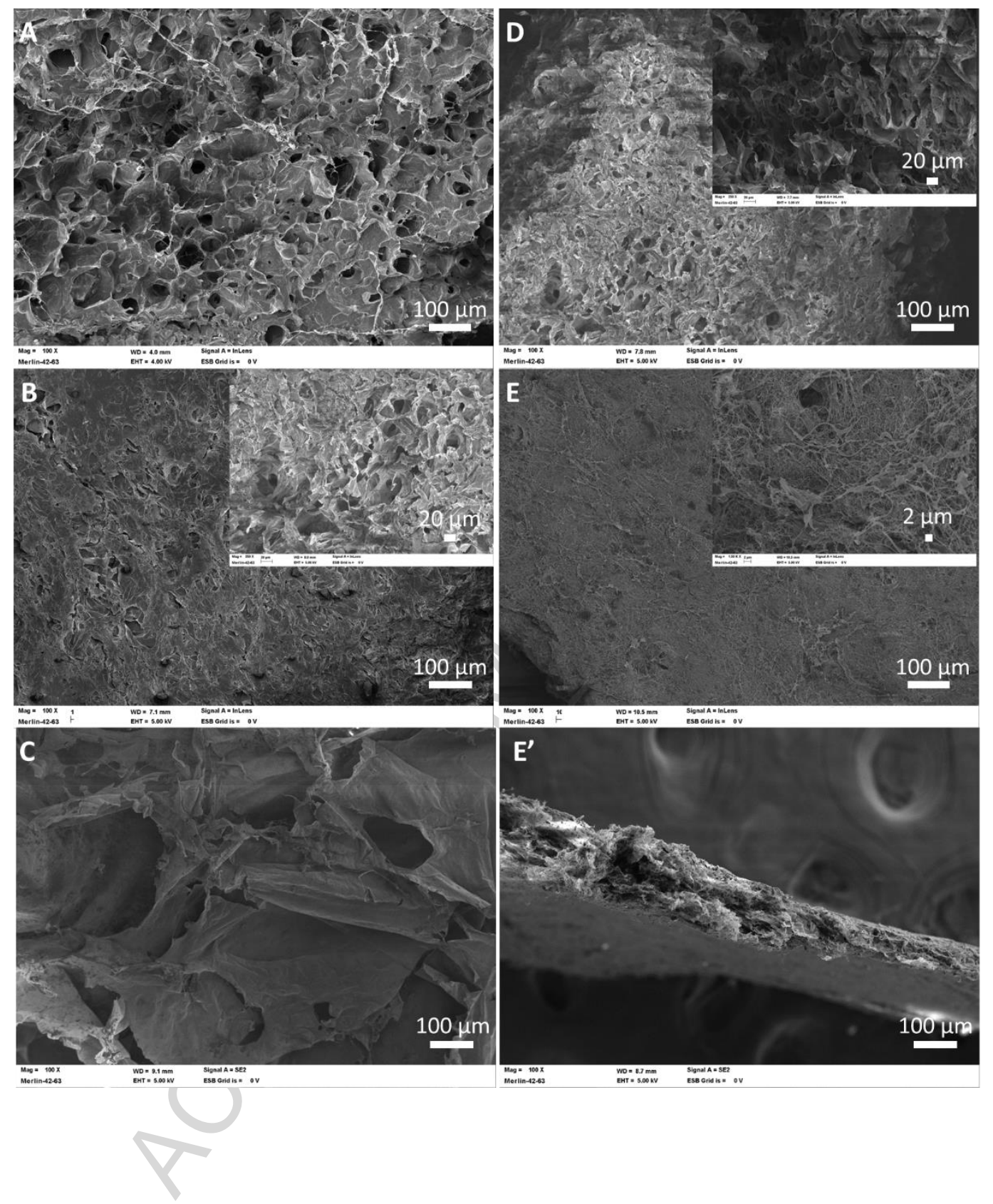


International Journal of Biological Macromolecules. Domínguez-Robles et al., 2018.

Fig. 7
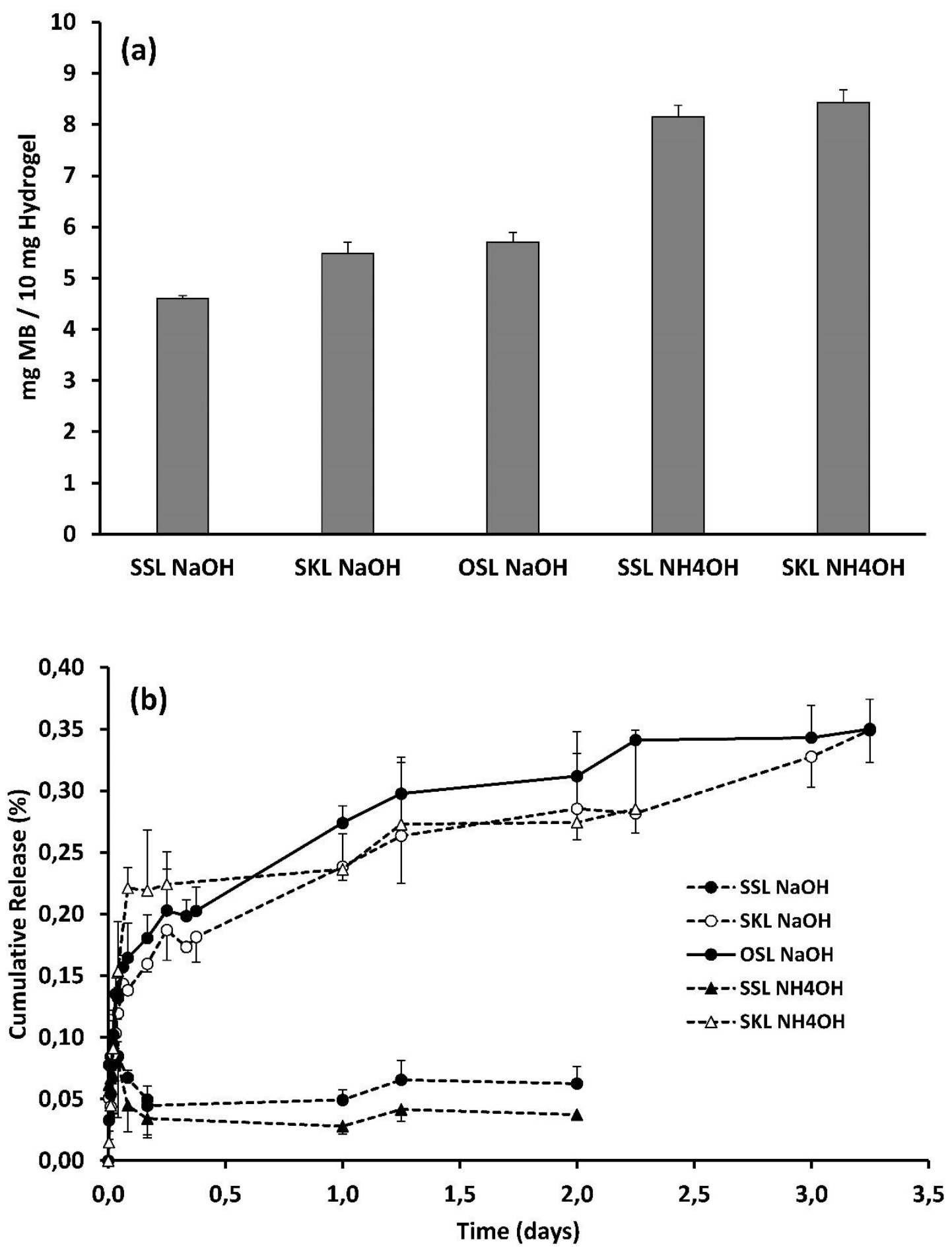


\section{Graphical abstract}

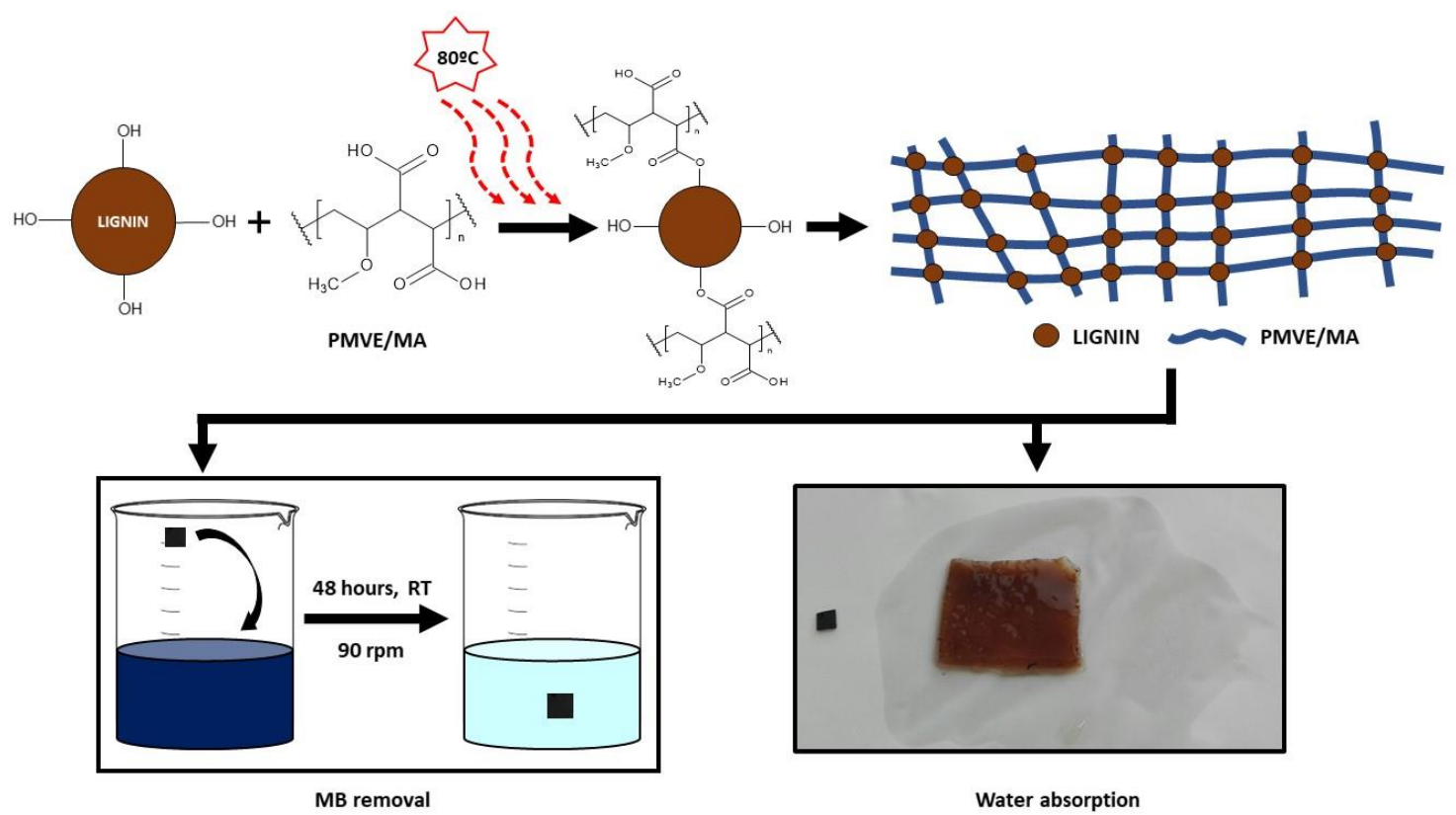




\section{Highlights}

- Technical lignins from three different processes were used to produce the hydrogels.

- Hydrogels were synthetized by crosslinking lignin with PMVE/MA.

- Lignins and hydrogels were deeply characterised.

- Structural features of lignin samples affected the performance of hydrogels.

- Lignin based hydrogels were used to successfully remove an organic dye. 